\title{
Advanced technology provides insight into marine habitats
}

\author{
Richard M. Starr
}

The pattern of boom and bust in major commercial fisheries has occurred many times around the world, and always with major economic consequences. A classic example is the sardine fishery in Monterey Bay. At the sardine fishery apex in the 1930s and 1940 s, more than 100 vessels harvested 700,000 tons of sardines and sold them to 19 canneries and 20 reduction plants - the largest assemblage of seafood processors in the Western Hemisphere. By 1952 the sardine population had plummeted, the fishery had collapsed and most of the canneries had closed.

Unfortunately, we are today seeing more and more examples of the bust side of the cycle. World catch of marine fishes peaked in 1989; since then dramatic declines have occurred in most of the world's most productive fisheries. Many of the collapses occurred before sufficient information was available for proper management. Often, fisheries grew and collapsed without knowledge of the basic biology and habitat requirements of important species.

In response to this need for information, Richard Starr, UC Sea Grant Extension Program Marine Advisor, and Gary Greene, director of California State University's Moss Landing Marine Laboratories (MLML), established the Center for Habitat Studies at MLML in 1995. The Habitat Center is a cooperative venture between the University of California Sea Grant Extension Program, MLML and the new campus of the California State University at Monterey Bay. Its purpose is to bring together scientists who use advanced technologies to provide insights into the spatial distribution and ecological value of coastal and marine resources.

A multidisciplinary team of marine researchers has formed at the Center to study habitat relationships of rockfishes, a diverse group that is one of the mainstays of commercial and recreational fisheries on the West Coast. The team deploys geophysical tools such as sidescan sonar to locate and characterize habitats on a large scale, then collects biological information using a manned submersible and acoustic equipment to quantify specific associations between species and habitats.

Greene, a geologist, leads the geophysical work. He has collected and

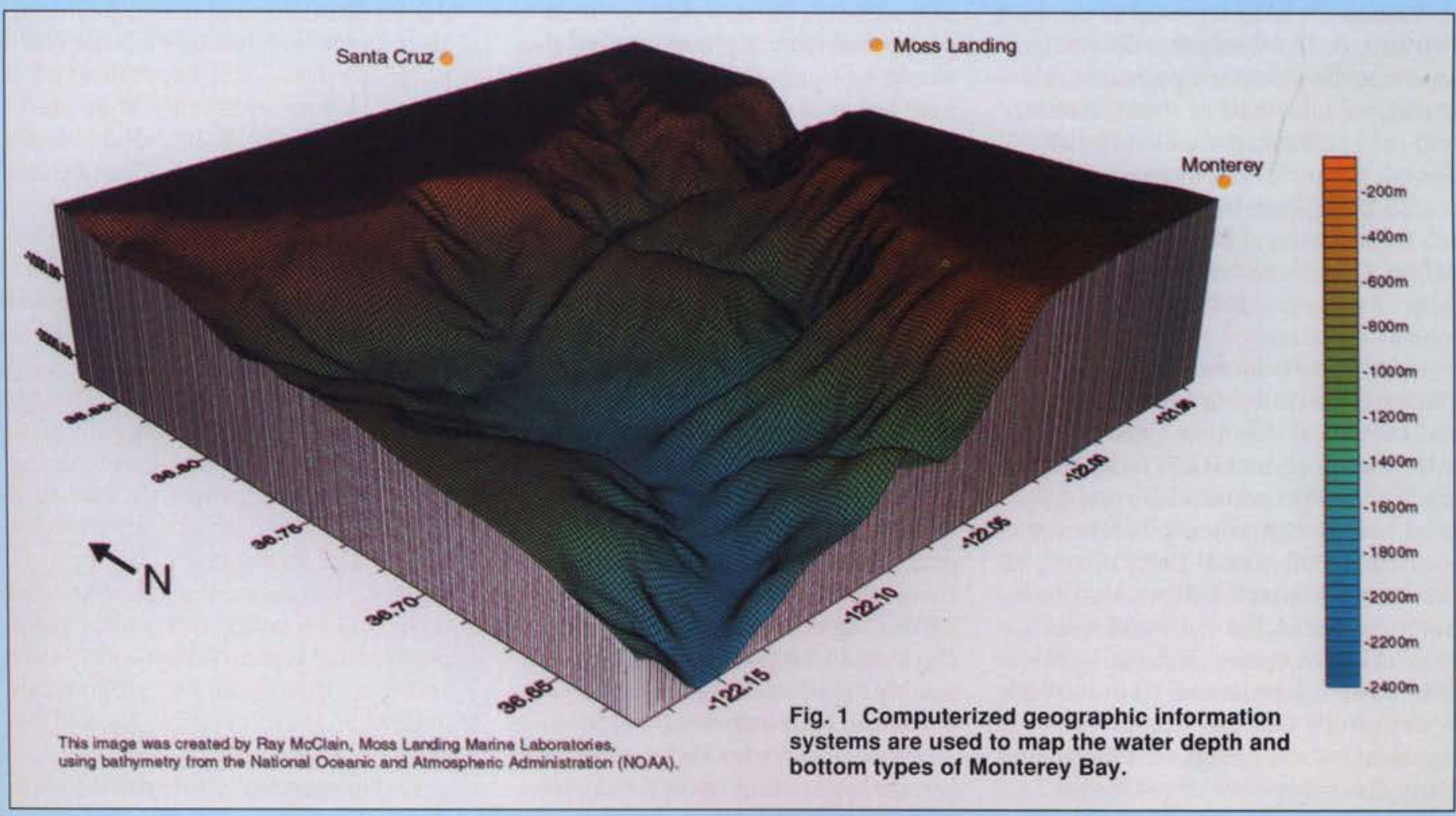




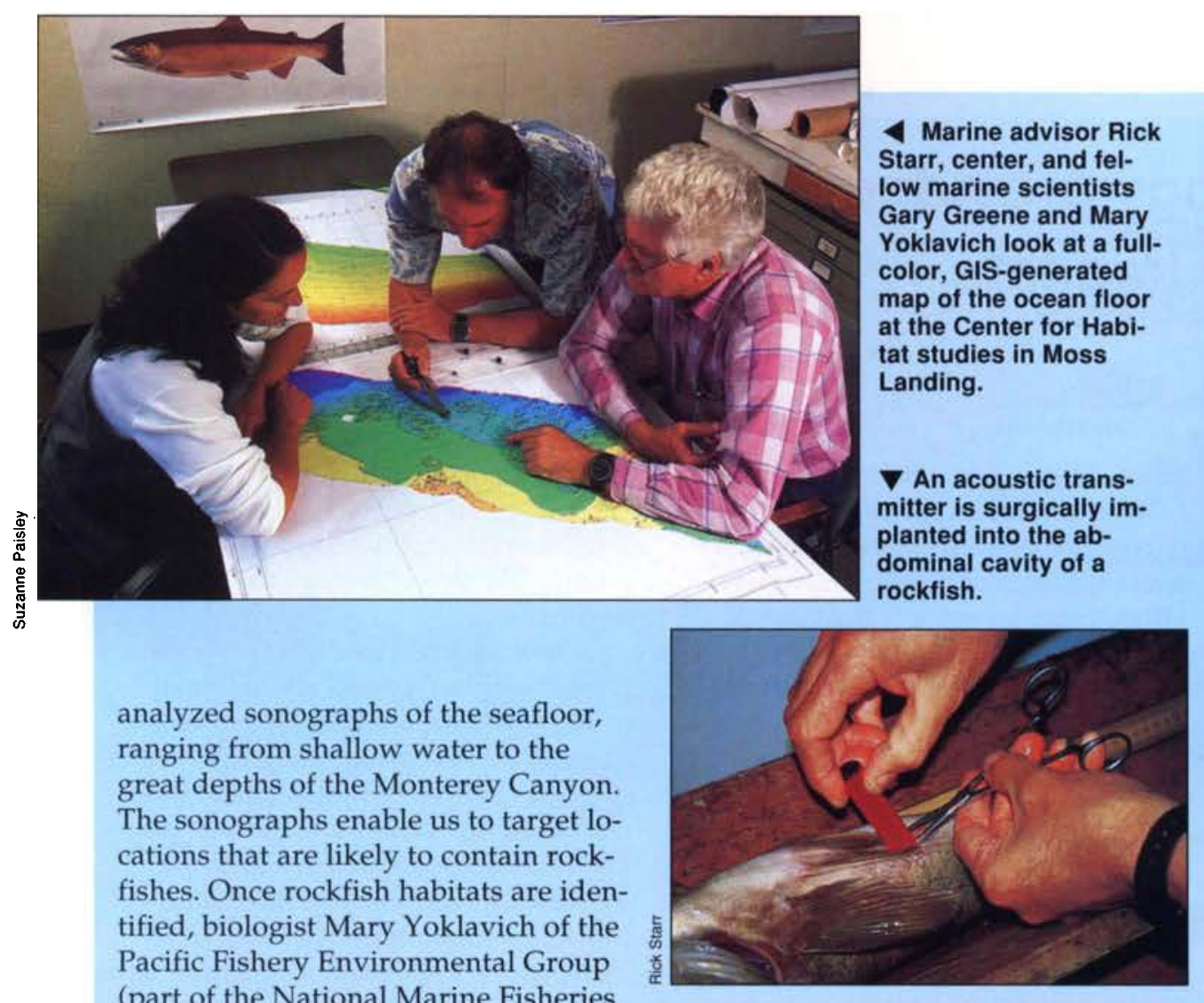

(part of the National Marine Fisheries Service) uses a manned submersible to collect biological observations. The submersible's pilot and a scientist conduct visual strip transects to identify species, describe fish behavior and count the number of animals observed in each transect. Paired lasers attached to the submersible are used to estimate fish length. The transect is also videotaped, and technicians painstakingly transcribe information about habitats and the exact location of every fish seen. Ichthyologists Gregor Cailliet from MLML, Bob Lea from the California Department of Fish and Game and Milton Love from UC Santa Barbara help identify species and provide ecological expertise.

Starr directs the next phase of analysis: the combination of ecological and biological data using geographic information system (GIS) technology (fig. 1). Computerized GIS systems are used to map bathymetry, habitats and rockfish distributions. Early results of the team's research indicate that rocky outcrops associated with undersea canyons form natural refugia - places where fish are protected from harvest. We observed that these relatively unfished habitats contained larger and more diverse species of rockfishes than did heavily fished areas. The dif-

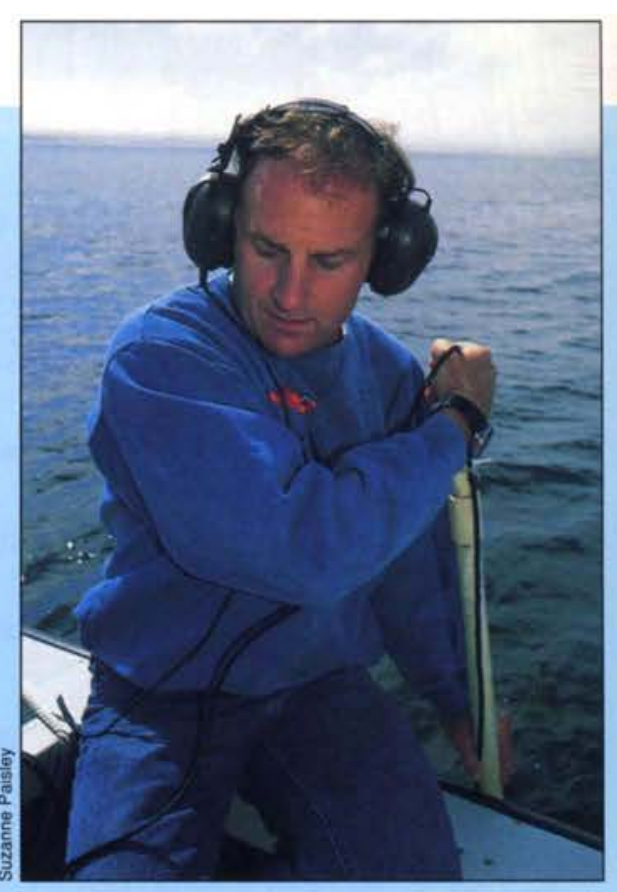

A Using global positioning system (GPS) coordinates, Starr tracks the tagged rockfish to determine their home ranges and frequency of movements.

ferences between heavily fished and lightly fished habitats led us to evaluate the potential of marine fishery reserves to enhance fisheries.

Marine fishery reserves are currently being proposed as alternatives to traditional fishery management practices in many places around the world (see page 33). Harvest refugia may enhance fisheries by increasing fish abundance and reproductive output in the reserve; contributing to recruitment inside and outside the protected area; maintaining species, genetic and habitat diversities; reducing user conflicts; and providing opportunities to field test ecological concepts related to protected areas.

The scientific community is divided in its debate over the value of refugia to enhance adjacent fisheries, however, because many of the fundamental assertions have not been tested. For example, a key assumption of reserve theory is that fish will remain in a reserve long enough to grow and reproduce, and that younger fish will ultimately "spill over" to unprotected areas and thus enhance local fisheries.

At the Center for Habitat Studies, we are conducting several research projects to evaluate reserve theory and provide information for fishery managers. We recently completed sidescan sonar surveys in the Big Creek Ecological Reserve to map benthic fish habitats inside and adjacent to the reserve. We next plan to use a submersible to estimate species composition, abundance and species/habitat relationships inside and adjacent to the reserve. This information will be used with information about ocean circulation to estimate the reproductive capability of rockfishes in the reserve.

As a second method of evaluating the effectiveness of reserves as a refuge for adult rockfishes, we are identifying home ranges and rates of movements of fishes in a proposed underwater park off Cannery Row and on the edge of the Monterey undersea canyon. We do this by first capturing and anesthetizing rockfish, then surgically implanting an acoustic transmitter into the abdominal cavity of each animal. We release the fish where they were caught, using differential global positioning system (GPS) coordinates, and track them with hydrophones to determine their home ranges and frequency of movements.

Our research at the Habitat Center should lead to better understanding of 


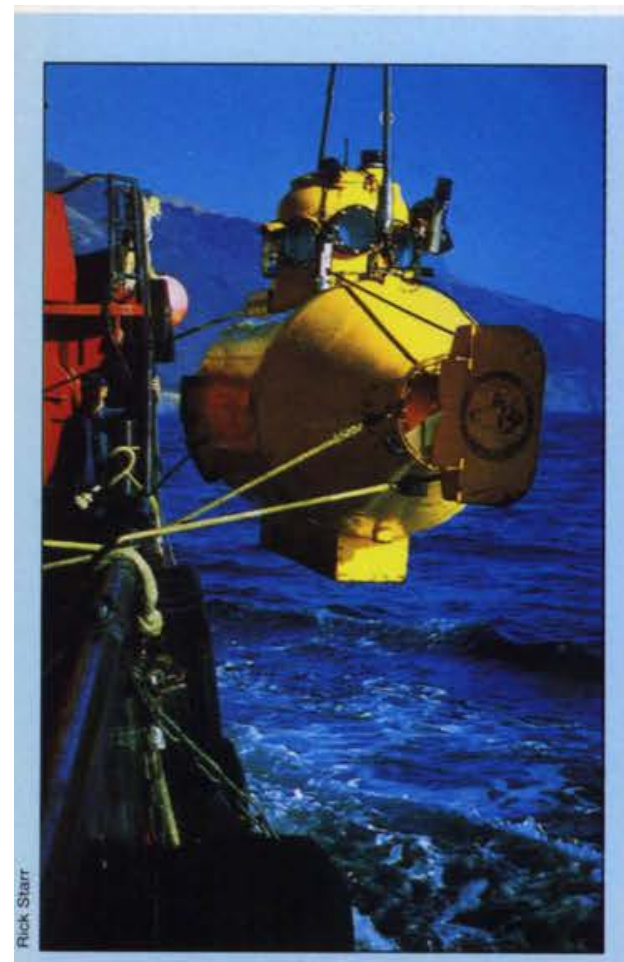

The submersible's pilot and a scientist conduct visual strip transects of rockfish habitats to identify species, describe fish behavior and count the number of rockfish observed in each transect.

the value of marine reserves and their potential for enhancing fisheries. We expect that the results will directly contribute to the effective management of marine fishery reserves in California and provide valuable information to fishery managers in all parts of the world.

R.M. Starr is UC Cooperative Extension, Sea Grant Marine Advisor for Monterey and Santa Cruz Counties.

\section{References}

McEvoy AF. 1986. The Fisherman's Problem: Ecology and Law in the California Fisheries, 1850-1980. New York: Cambridge Univ $\mathrm{Pr}$.

Rowley RJ. 1994. Marine reserves in fisheries management. Aquat Conserv: Marine Freshwater Ecosys 4:233-54.

Starr RM, Fox DS, Hixon MA, et al. 1996. Comparison of submersible and acoustic estimates of fish density on a rocky bank. Fish Bull 94:113-23.

Yoklavich MM, Cailliet GM, Greene HG, Sullivan D. 1995. Interpretation of sidescan sonar records for rockfish habitat analysis: Examples from Monterey Bay. Alaska Dept. Fish and Game Special Publication No. 9:11-5. continued from p. 40

extinction are the most extreme examples. Recovering endangered species requires identification of the causes of decline, and there is almost inevitably some confounding of natural and human causes. We simply don't know enough to untangle the threads. For example, the dams on the Snake River, where endangered stocks of Columbia River chinook salmon spawn, were completed in the mid1970 s, about the same time as the regime shift in the northeast Pacific. Another example, closer to home, is the decline in coho salmon over the past decade, during the period following the regime shift in the $1970 \mathrm{~s}$, but accompanied by increasing diversions in California's coastal streams and, until recently, by high harvest rates.

One possible cause of major alterations in the biological productivity in California's coastal ocean is climate change, which could cause dramatic changes in coastal populations by increasing the frequency or intensity of ENSO events, or by increasing upwelling (Bakun 1990). The decline in zooplankton biomass off Southern California is an example of long-term change that may be due to change in climate.

The advances of the past several decades have brought us closer to the answers we need by sharpening our focus on the time and space scales at which important processes operate. Ecologists, oceanographers and meteorologists realize that an important requirement for solving a problem is choosing the proper temporal and spatial scale at which to approach it. One example is the recent appreciation of the fact that large changes in marine environments are taking place on a global scale. The apparent synchrony of various dramatic shifts in population abundance in different parts of the world, and a realization of the possible atmospheric linkages across ocean basin scales, are allowing us to link events that previously seemed isolated.

This increase in the scope of marine population questions may encompass some of the keys to understanding these shifts in abundance. One advan- tage of a global perspective is the gain in analytical power possible through a comparative approach. Conclusions are often hampered by the limited time spans of available population data. By increasing the number of "experimental replicates" through a comparative approach, we have essentially increased the amount of available data. In addition to the shift in focus of spatial scale, oceanographers have recently realized that biological processes change on longer time scales (50 years or more), most likely in response to large-scale fundamental changes in the physical state of the atmosphere and ocean.

Another shift in the scale of research focus is our increased awareness of the importance of circulation near promontories and changes in upwelling on weekly time scales in maintaining coastal populations and biological communities. Even though we are interested in changes in recruitment from year to year, we need to look within years to describe the mechanisms responsible for longer term changes. With regard to spatial scales, we are interested in population levels and ecosystem health along the entire coast, but we may be able to manage better by taking advantage of the variability in productivity and circulation on much smaller scales, such as those shown in figure 3 . One growing trend in the management of coastal ecosystems is the use of protected areas or reserves. The design of management strategies involving protected areas requires understanding variability in productivity and larval dispersal on these scales.

UC and Sea Grant will continue to contribute to the solution of problems in the coastal ocean. There is every indication that Sea Grant will continue to support research on how changing ocean conditions affect biological resources. Other planned programs include the Coastal Ocean Processes in the National Science Foundation (NSF) and the GLOBEC program of NSF and the National Oceanic and Atmospheric Administration (NOAA). Both of these programs are starting up this year, and will run over the next 5 to 10 years. International linkages are being 